\title{
In vitro Micropropagation of Datura metel L. through Somatic Embryos from Root Explants
}

\author{
P. Nithiya* and D.I. Arockiasamy \\ Department of Plant Biology and Plant Biotechnology, St. Joseph's College, \\ Trichirappalli-620002, India
}

Key words: Somatic embryos, Root explants, Micropropagation, Datura metel

\begin{abstract}
A simple reproducible protocol has been reported from root explants for in vitro micropropagation of Datura metel through somatic embryos. A large number of somatic embryos were developed from these explants on MS supplemented with BAP $4.0 \mathrm{mg} / 115$ days after inoculation. Subsequently all embryos developed into plants while they were attached to the explants. Fast shoot elongation and root growth were achieved in MS containing BAP $2.0 \mathrm{mg} / \mathrm{l}, \mathrm{GA}_{3} 1.0 \mathrm{mg} / \mathrm{l}$ and IBA $1.0 \mathrm{mg} / 1$. These plantlets had a well developed tap root system and hundreds of plantlets could be easily separated from the initial root explants. The well rooted plantlets were hardened in plastic cups containing sterilized vermiculite, garden soil and farmyard soil $(1: 1: 1)$. These plants were successfully transferred and grown in the soil mixture after two weeks with a survival rate of $90 \%$. The protocol developed should prove to be highly promising to produce large quantities of plants in a short period of time.
\end{abstract}

\section{Introduction}

Plants play an important role in human life to combat disease since time memorial. India is one of the 34 mega biodiversity centers on earth due to highly varied edaphic and climatic regions. In spite our share in the world medicinal plants trade is just $0.5 \%$. The major reasons pointed out for this status is an inconsistence in the quality and contaminations in the products. One of the reasons which is also responsible for the loss of several medicinal plant species is the dependence on the natural population for our medicinal plant needs. Unscientific collection practice is yet another reason for the loss of biodiversity and precious medicinal plants. One such species is Datura metel (violet flowered) (Fig. 1a) with a high medicinal value and is becoming rare in natural habitat (Muthukumar et al. 2000). The whole plant is used as anthelminitic, anticancer, antispasmogenic, blood pressure depressant, strong nematicidal, anticholinergic, antiviral and analgesic (Chopra et al. 1956, Sharma et al. 1996). Indiscriminate collection of plants of Datura metel has resulted in the present sparse distribution

${ }^{*}$ Corresponding author. E-mail: nithy_pappu@yahoo.co.in 
of this highly prized medicinal plant species. Since all plant parts are medicinally useful the whole plants are uprooted from the natural population for medicinal use. This plant species is becoming rare in its natural habitat and warrants urgent conservation measures.

In view of the dwindling population of highly valuable medicinal plants immediate steps need to be taken by the farmers supported by concerned authority for conserving the natural population of these sparsely distributed plants species. Conservation and large scale propagation will not only provide valuable plant material to local pharmaceutical industry but also open up a vista for the country to compete in the global medicinal plant market. Plant tissue culture is a tool which ensures mass production of plants for ex situ conservation and their improvement (Thomas and Puthur 2004, Purchoa and Ramburn 2004). Muthukumar et al. (2000) studied in detail in situ regeneration and production of somatic embryos of this plant species using various types of explants. The present study reports production of plantlets from somatic embryos in large quantities directly from root explants.

\section{Materials and Methods}

Seeds of Datura metel L. were collected from the Kolli hills Namakkal (Dt.) Tamil Nadu. After surface sterilization they were kept under running tap water for about $2 \mathrm{hrs}$ and then washed with 5\% detergent (Teepol) for 10 minutes following with $2 \%$ Bavistin (fungicide) for 10 minutes and finally with $0.1 \%$ $\mathrm{HgCl}_{2}$ ). The seeds were washed thoroughly with sterile double distilled water. Sterilization steps except running tap water wash were carried out inside the laminar. Sterilized seeds were inoculated on the MS basal medium for germination. From the in vitro grown seedlings the root explants were collected and inoculated on MS with BAP, AdS and $\mathrm{Kn}$ in various concentrations (1.0 - 4 $\mathrm{mg} / \mathrm{l})$. For quick shoot elongation and root growth the MS supplemented with BAP $(1.0-4.0 \mathrm{mg} / \mathrm{l})$ and $\mathrm{GA}_{3}(1.0-4.0 \mathrm{mg} / \mathrm{l})$, IBA and IAA $(0.5-2.5 \mathrm{mg} / \mathrm{l})$ was used. Cultures were maintained at $25 \pm 2^{\circ} \mathrm{C}$ and $16 \mathrm{hrs}$ photoperiods.

\section{Results and Discussion}

The present study was undertaken in an attempt to produce plants in large numbers from root explants through direct somatic embryos. Somatic embryos emerged directly from the explants in 15 days after inoculation (Figs. 1c-f). A high frequency of direct embryogenesis was obtained on MS containing BAP $(4.0 \mathrm{mg} / \mathrm{l})$; and the frequency ranged between 50 and 90 embryos per explant, the average being $87 \pm 6$ per explant at $4.0 \mathrm{mg} / 1 \mathrm{BAP}$ (Fig. 1g).

Somatic embryogenesis was also tried in Kn and AdS supplemented media. Maximum responses (55\%) as well as maximum number of embryos (72 \pm 9 ) 
were obtained on MS containing $4.0 \mathrm{mg} / 1 \mathrm{Kn}$. Similarly, maximum responses $(45 \%)$ as well as maximum number of embryos $(47 \pm 3)$ were observed in 4.0 $\mathrm{mg} / \mathrm{l}$ AdS. In all the three cases there is a positive correlation between concentration and the response. A comparative analysis shows that among the three hormones BAP was the most efficient one in producing somatic embryos followed by $\mathrm{Kn}$ and AdS (Table 1). Direct somatic embryogenesis has been reported in the young leaves of an orchid (Oncidium sp.). Clusters of somatic embryos were produced directly from epidermal and mesophyll cells of leaf tips and cut surfaces within one month, when cultured on a Gelrite ${ }^{\mathrm{TM}}$-gelled half strength MS supplemented with $0.3-1.0 \mathrm{mg} / 1$ of thidiazuron (Chen et al. 1999). Marla et al. (1996) also produced direct somatic embryos from cotyledonary explants. Indirect somatic embryogenesis has been reported on root explants of different rice varieties on MS containing BAP $2.0 \mathrm{~g} / 1$ and NAA $0.5 \mathrm{mg} / 1$ (Asit et al. 2003).

Table 1. Direct somatic embryogenesis from root explants grown in different concentrations of supplements, BAP, Kn and AdS.

\begin{tabular}{cccc}
\hline $\begin{array}{l}\text { BAP, Kn and } \\
\text { AdS conc. } \\
\text { (mg/l) }\end{array}$ & $\begin{array}{c}\text { No. of explants } \\
\text { responded/total No. of } \\
\text { explants inoculated }\end{array}$ & $\begin{array}{c}\text { \% of } \\
\text { response }\end{array}$ & $\begin{array}{c}\text { No. of } \\
\text { embryos/culture }\end{array}$ \\
\hline BAP & $13 / 20$ & 65 & $60 \pm 5$ \\
1 & $14 / 20$ & 70 & $65 \pm 3$ \\
2 & $17 / 20$ & 85 & $79 \pm 4$ \\
3 & $20 / 20$ & 100 & $87 \pm 6$ \\
4 & & & \\
Kn & $6 / 20$ & 30 & $45 \pm 5$ \\
1 & $7 / 20$ & 35 & $54 \pm 2$ \\
2 & $9 / 20$ & 45 & $63 \pm 6$ \\
3 & $11 / 20$ & 55 & $72 \pm 9$ \\
4 & & & $20 \pm 2$ \\
AdS & $3 / 20$ & 15 & $26 \pm 3$ \\
1 & $5 / 20$ & 25 & $34 \pm 7$ \\
2 & $6 / 20$ & 30 & $47 \pm 3$ \\
3 & $9 / 20$ & 45 & \\
4 & & & \\
\hline
\end{tabular}

Embryos were transferred to MS with different concentrations of $\mathrm{GA}_{3}$ and BAP for the development of embryos. A combination of $1.0 \mathrm{mg} / 1 \mathrm{GA}_{3}$ and 2.0 $\mathrm{mg} / 1 \mathrm{BAP}$ was found to be ideal for shoot elongation. Similar results were reported by Kawata and Ishihara (1968), Sticklen (1991) and Kavikishor (1986).

Growth of roots was restricted even after sufficient shoot elongation (> 4 $\mathrm{cm})$. The embryos were transferred to MS containing different concentrations (0.5 $-2.5 \mathrm{mg} / \mathrm{l}$ ) of IBA. IBA was found to be far superior in promoting root growth specially at $1.0 \mathrm{~g} / \mathrm{l}$, and the percentage of response was 92 (Fig. 1h, Table 2). 
Jayakumar and Jayabalan (2002) reported similar results on rooting from the microshoots of Psordea corylifolia on MS containing IBA (1.0 mg/l). Root elongation was observed on the third day from the date of the embryo transplantation and well-developed tap root system was observed in 15 days. After 15 days plants were ready for hardening.
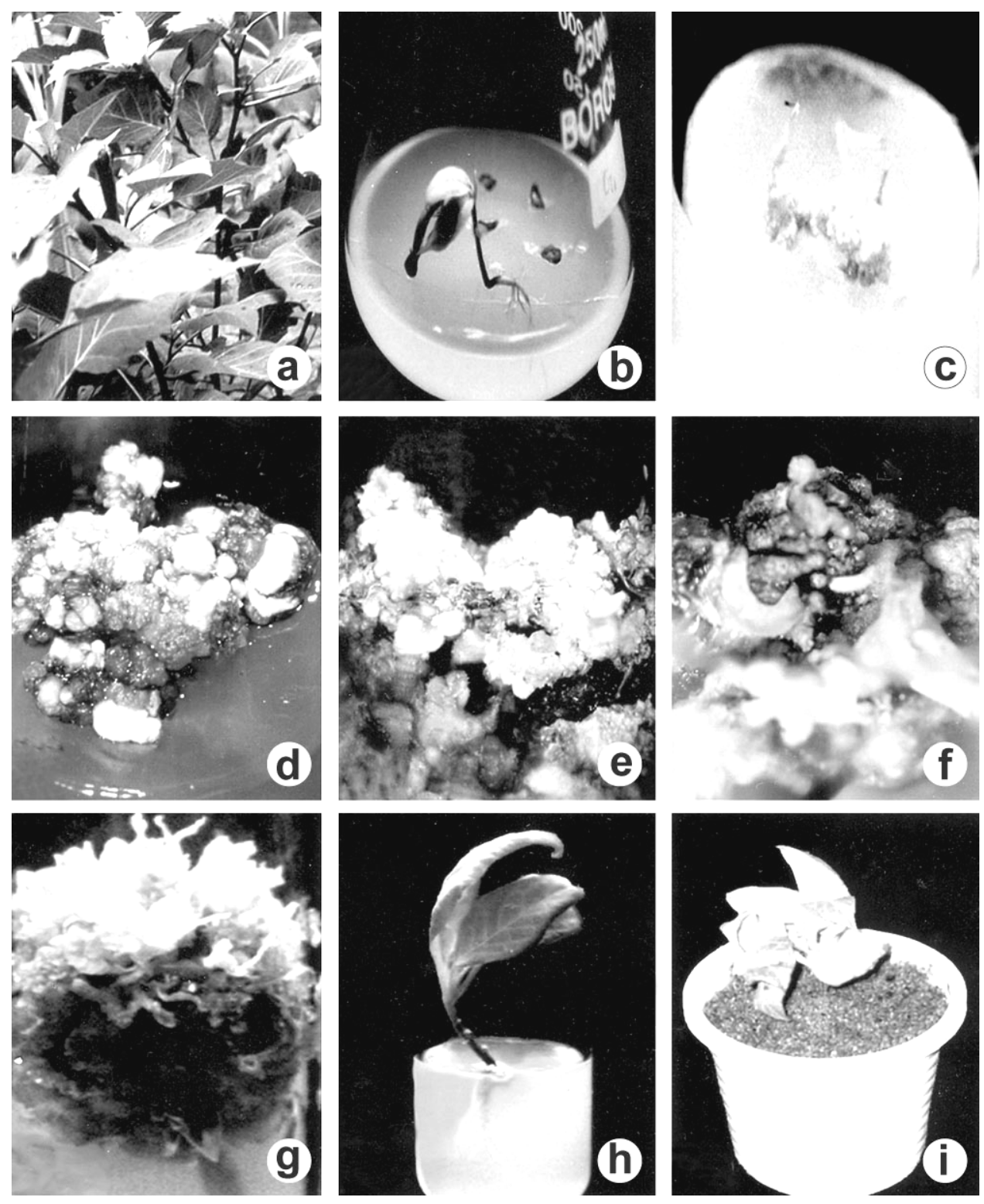

Fig. 1a-i: a. Habit, b. In vitro seed germination, c. Root explants, d-f. Stages of development of somatic embryos, g. Developed from somatic embryos, h. Well rooted plant, i. Hardened plant. 
After two weeks, plants were removed from the agar medium and washed thoroughly with tap water and dipped in MS basal liquid medium without carbon sources for an hour. Finally they were transplanted to the sterile vermiculite and irrigated with half strength MS basal liquid medium without

Table 2. Effect of IBA on root elongation from embryo-derived shoots.

\begin{tabular}{lcc}
\hline $\begin{array}{l}\text { IBA } \\
(\mathrm{mg} / \mathrm{l})\end{array}$ & $\begin{array}{c}\text { \% of } \\
\text { response }\end{array}$ & $\begin{array}{c}\text { Root length/shoot } \\
(\mathrm{cm})\end{array}$ \\
\hline 0.5 & 78 & $10 \pm 4$ \\
1.0 & 92 & $13 \pm 3$ \\
1.5 & 85 & $11 \pm 2$ \\
2.0 & 68 & $9 \pm 5$ \\
2.5 & 57 & $6 \pm 2$ \\
\hline
\end{tabular}

sucrose. The plants were transferred to the plastic cups containing sterilized vermiculite, garden soil and farmyard soil (1:1:1) (Fig. 1i). After 15 days of hardening the survival rate was $85 \%$. Hardened plants were planted in the garden and the survival rate was $60 \%$ after a month. The protocol proved to be promising for the production of any number of plants from root explants directly in a short time, which means a faster procedure than the one previously tried for production of somatic embryos through callus.

\section{References}

Asit B Mandal, Aparna Maiti and Anusrita Biswas (2003) Somatic embryogenesis in root derived callus of India rice. Plant Tissue Cult. 13(2): 125-133.

Chopra RN, Nayar SL and Chopra IC (1956) Glossary of Indian medicinal plants. CSIR, New Delhi. 1: 334.

Chen JT, Chang C and Chang WC (1999) Direct somatic embryogenesis on leaf explant of Oncidium 'Grower Ramsey' and subsequent plant regeneration. Plant Cell Rep. 19(2): 143-149.

Marla L, Binzel N, Sankhla Sangeeta Joshi and Daksha Sankhla (1996) Induction of direct somatic embryogenesis and plant regeneration in pepper (Capsicum annuum L.). Plant Cell Rep. 15(7): 536-540.

Jayakumar $\mathbf{M}$ and Jayabalan $\mathbf{N}$ (2002) In vitro regeneration of Psoralea corylifolia L., using petiole explant - A rare medicinal herb. Conver. 4: 15-18.

Kavikishor PB and Reddy GM (1986) Regeneration of plants from long term root and embryo derivative callus cultures. Curr. Sci. 55: 664-665.

Kawata S and Ishihara A (1968) The regeneration of rice plants Oryza sativa L. in the callus derived from the seminal root. Proc. Japan Acad. 44: 549-553.

Muthukumar B, Arockiasamy DI and John Britto (2000) In vitro propagation of Datura metel L. from hypocotyl explants. Plant Tissue Cult. 10(1): 39-44. 
Purchoa D and Ramburn R (2004) A study on the use of Carrot juice in the tissue culture of Daucas carota. Aftr. J. Biotech. 3(4): 248-254.

Sharma PV (1996) Classical uses of medicinal plants. Chaukhambha Visvabharati Varanasi, India 201.

Sticklen MB (1991) Direct somatic embryogenesis and fertile plants from rice root cultures. J. Plant Physiol. 138: 577-580.

Thomas T Dennis and Jos T Puthur (2004) Thidiazuron induced high frequency shoot organogenesis in callus from Kigella pinnata L. Bot. Bull. Acad. Sci. 45: 307-313. 